rules, and in particular its appeals system. Unlike the US Patent and Trademark Office, where appeals are heard in a federal court, the European appeals system is based on inhouse 'technical' hearings.

The patent conflicts with a new EU directive on patenting biotechnological processes, which excludes genetic modifications of human embryonic stem cells from being patented. But although the EPO belongs to an organization of 19 European states, it is not part of the EU, allowing the patent - in principle - to be legally valid. The EPO has agreed, however, to adapt the directive to its own rule of behaviour.

The EPO immediately conceded its error after the case became public last week. According to Christian Gugerell, director of biotechnology at the EPO, the application had not been investigated thoroughly enough. "The English wording of the claim should have included the qualification 'nonhuman', because in English scientific usage the term 'animal' [is normally taken to] include 'human," he says.

But Christoph Then, principal campaigner against genetic engineering at Greenpeace Germany, is sceptical about the EPO's claim that the mistake was merely the result of a lack of thought. "Given the explicit wording of the patent claim, it is out of the question that the application has simply 'slipped through",' he says.

Greenpeace activists last week bricked up the entrance to the EPO, blocking access for several hours. They hope the case will boost worldwide protests against the patenting of life forms. Controversial applications currently being processed include the technology used to produce 'Dolly' the sheep (see Nature 403, 351; 2000).

Quirin Schiermeier

\title{
US energy agency pulls plug on role in genome project
}

\section{Washington}

Scientists at the US Department of Energy (DoE) say they will stop large-scale human gene sequencing later this year, when a preliminary draft of the human genome sequence is due to be completed.

The department took the lead in initiating the Human Genome Project in the mid-1980s, but has since become a minority participant in what is now a global project.

The Joint Genome Institute (JGI) - a powerful sequencing centre established by several DoE laboratories at Walnut Creek in California - will continue with limited sequencing to refine the human genome data, but is planning a new work programme for 2001.

"We see ourselves as being out of the human genome and the bulk of the mouse genome by October or so," says Elbert Branscomb, JGI's director.

The DoE's division of biological and environmental research, which runs its component of the genome project, will meet with its genome contractors this week in Santa Fe, New Mexico, to begin planning the division's new programme.

Ari Patrinos, head of the division, says that the new research effort will focus on proteomics and structural biology, work which will rely on two areas where DoE laboratories are stronger than most universities: large facilities — such as high-powered light sources - and computational science.

Some DoE scientists claim the move is driven in part by the department's exasperation at the extent to which its main US partner, the National Human Genetics Research Institute (NHGRI) at the National Institutes of Health (NIH), has claimed most of the credit for the project.

NHGRI has received large budget increases, driving the DoE share of the project — worth about $\$ 90$ million a year down from an initial one-third of the US project to about one-fifth. But Patrinos says the DoE will maintain its investment at $\$ 90$ million "for the next couple of years" and collaboration with NHGRI will continue.

Patrinos acknowledges that some individuals at the DoE are worried that the final summary paper publishing the draft sequence will fail to acknowledge the department's role in the project. But he says that he is "philosophical" about this prospect.

As the relationship with NHGRI weakens, Patrinos hopes to strengthen links with two other NIH institutes, the National Cancer Institute and the National Institute of General Medical Sciences.

The JGI hopes to move on to study other genomes related to human health and environmental problems.

Branscomb says that up to a quarter of its capacity may be used to sequence microbes that have the capacity for bioremediation or for sequestering atmospheric carbon. He also hopes to win support for the sequencing of other vertebrate genomes for comparison with the human sequence. Colin Macilwain

\section{Australian jailed for removal of fossilized footprints}

\section{Sydney}

Australian authorities have sent a strong warning to those who trade illegally in fossils by jailing a man for two years for removing and trying to sell a dinosaur footprint and two human footprints.

Michael Latham, an Aborigine from the town of Broome, Western Australia, confessed that he had used an angle grinder to cut a block containing the dinosaur footprint when it was exposed at low tide. On a disability pension and needing money to support his family, he offered the footprint to a collector for $\mathbf{A} \mathbf{2 5 0 , 0 0 0}$ (US\$153,000), but later dropped the price to A $\$ 100,000$.

He also extracted two fossilized human footprints from another site, thought to be 7,000 years old. A local cattle farmer, accused of receiving these, was acquitted.
John Long, an expert in dinosaur fossils and Curator of Vertebrate Palaeontology at the Western Australian Museum, Perth, says the Megalosauropus footprint is about 120

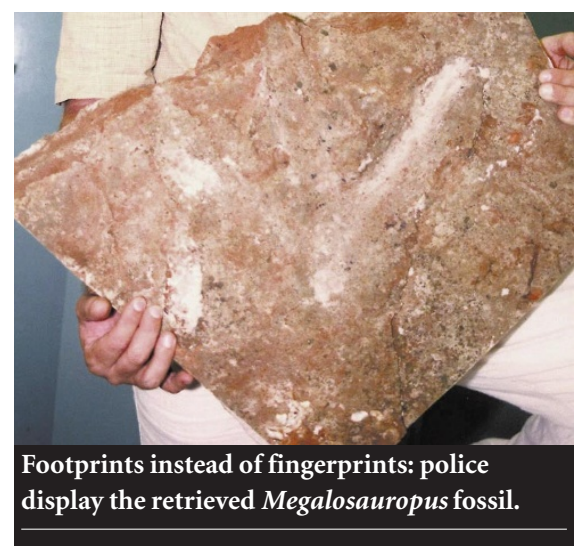

$\approx \odot 2000$ Macmillan Magazines Ltd million years old, and was probably made by a carnivorous dinosaur up to nine metres long and similar to Allosaurus. "Broome is one of the world's most significant sites for dinosaur footprints of the early Cretaceous, but there is no protection for them," says Long (see Nature 403, 687, 689-690; 2000).

Such fossils have great spiritual significance to local Aborigines - who expressed their displeasure by throwing one of the human footprints back into the sea. Sentencing Latham, Judge John Wisbey said: "I'm in no doubt you were well aware of their importance to your people".

The state of Western Australia is considered the legal owner of the dinosaur footprint, since it came from below the high-water mark. It is being kept in the police station until its future location has been agreed.

Peter Pockley 